\title{
Psychological Aspects of Breast Reconstruction after Breast Cancer
}

\author{
Anna Pittermann Christine Radtke \\ Department of Plastic and Reconstructive Surgery, General Hospital Vienna, Medical University of Vienna, Vienna, Austria
}

\section{Keywords}

Breast cancer surgery · Psychosocial aspects .

Patient-oriented treatment $\cdot$ Reconstructive surgery

\section{Abstract}

Even though breast cancer mortality is declining, the diagnosis still poses a huge threat for the affected woman and her close family. Breast cancer surgery, which often includes reconstructive procedures, can help restoring a satisfactory body image. The decision on the type of surgery should always be made together with the patient and should focus on her psychosocial needs. This review describes the psychological aspects of breast cancer for the patient and her social environment and offers ideas for a patient-oriented treatment plan.

(c) 2019 S. Karger AG, Basel

\section{Introduction}

Breast cancer is the most common cancer in women in the industrialized world [1]. Currently, a woman living in Germany has a 1 in 13 lifetime risk of developing breast cancer [2], with around 69,000 new cases diagnosed every year [3].

Of the women diagnosed with this malignancy, almost $30 \%$ are younger than 55 years [3], which means that breast cancer affects women earlier in their lives than other cancers. Fortunately, even if the incidence of breast cancer is rising, breast cancer mortality is declining [4] thanks to early detection and improved and new treatment modalities (e.g., immunotherapies, checkpoint inhibitors, etc.).

The treatment of breast cancer often includes some kind of surgical procedure, either breast-conserving sur- gery, mastectomy alone, or mastectomy with breast reconstruction (immediate or delayed), often combined with either a neoadjuvant or adjuvant concept. Due to the central meaning of the female breast for a woman's selfidentity and body image, it is inevitable to take a closer look at the psychological impact of such a treatment. The aim of this review is to stimulate the reflection on intrapsychic aspects of breast cancer surgery.

\section{The Psychological Meaning of the Female Breast}

The female breast has an influence on a woman's self-perception but also on how a woman is perceived by the society, by others. The breast is associated with aspects of femininity, motherhood, and sexuality and very often represents the most dominant sexual characteristic of women because it is visible to the external world. The breast is an important aspect of the female body image. The subjective body image is the result of perceptions, thoughts, feelings, and the individual patient history [5].

Because of the meaning of the female breast, different options for reconstruction are an important step in the patient-oriented treatment of breast cancer. Nevertheless, all the surgical possibilities should not distract from the potential psychosocial sequelae associated with the diagnosis and treatment.

The reconstruction of the breast, no matter if immediate or delayed, cannot protect the woman and her family from the psychological disturbances related to breast cancer. Therefore, it is important for the patient and her social environment, including the treating surgeon, to be aware of the psychosocial aftermaths of breast cancer.

\section{KARGER}

๑) 2019 S. Karger AG, Basel
Dr. Mag. Anna Pittermann

Department of Plastic and Reconstructive Surgery, General Hospital Vienna

Medical University of Vienna, Währinger Gürtel 18-20

AT-1090 Vienna (Austria)

E-Mail anna.pittermann@akhwien.at 


\section{Psychosocial Responses to Breast Cancer}

Although the mortality rates due to breast cancer are declining, the diagnosis of a malignancy evokes psychological distress and fear [6,7]. Affected women start to focus on issues of illness, vulnerability, death, and end of life. To deal with these strains, every woman should be offered psychological support [8]. Following breast cancer surgery and mastectomy, most women feel less confident about their body and lose their self-esteem; moreover, identification with the new body image is often difficult, and women need time to accept their new appearance.

Breast cancer does not only affect the patient but the entire family. Partners of affected women try to support their wives but, at the same time, have to deal with their own fears about the future, physical changes their wives are going through, or fears about a possible recurrence of the disease [9]. Especially in families with small children, partners often have to take over family responsibilities which they have not had before and which represent additional stressors. Partners might experience a change in their intimate relationships with their wives or even a change in sexuality or sexual dysfunction $[10,11]$.

Children of cancer patients experience the illness of their mother as a threat that comes along with many changes and distress, which might consecutively lead to behavioral changes and strong emotional reactions [12].

Finally, breast cancer is a disease that also affects the female relatives of the patient. Mothers, grandmothers, sisters, and daughters have to face the risk of a hereditary predisposition. They may have undergone a similar treatment or live with the fear of developing the same disease in the future. Also, feelings of guilt for passing breast cancer on or because of not having to go through the same disease might create psychosocial distress within the family system.

Since breast cancer affects the whole family, psychological support should focus on this and might include several family members if necessary.

\section{Psychosocial Implications of Breast Cancer Surgery}

Having to face a life-threatening disease changes the way women reflect on their lives and can also change what is most appreciated in life [13]. For many patients, health becomes more valuable than cosmetic considerations, and they, therefore, more often formulate their wish for a "normal" looking breast rather than for a breast that is "good" looking. The understanding of "normality" might be quite individual [14], but, in general, women ask for reconstructive methods that help them not being perceived as "different" from other women (for example, in social situations such as swimming) and that enable them to wear clothing without looking physically asymmetric. Also, being able to see oneself in the mirror without instantly being reminded of the disease might be a motivation for reconstructive surgery.

Breast reconstruction offers the opportunity to restore a satisfactory self-image, and Pikler and Winterowd [15] describe in their study that women with breast cancer who describe their body image more favorably do overall cope better with the course of the illness. Important considerations when choosing the reconstructive procedure seem to be to limit the time of the "breast-free" interval to a minimum, to have as few surgeries as possible, and to make the decision in agreement with important others $[16,17]$. Regarding the material used for the reconstruction, many women tend to favor their own tissue over silicone implants, but donor site scaring can become an area of dissatisfaction [18].

Numerous studies deal with the decision-making process regarding the choice of the reconstructive method and with the psychosocial effects of the different methods [19-21], without leading to a clear result. Jabłoński et al. [10] demonstrated in a recent study that surgical treatment of breast cancer significantly interferes with the way patients perceive their body before and after the intervention. Independent of the surgical procedure, i.e., mastectomy or breast-conserving therapy, the risk of a low selfacceptance and of difficulties in experiencing an intimate relationship with the partner is present. It is controversially discussed if immediate or delayed reconstruction leads to a better psychological outcome. Methodologies of studies evaluating psychological outcomes show high variability, making it difficult to compare results [19].

To which degree a woman is irritated by the absence or the different appearance of her breast can vary enormously from patient to patient. The first look into the mirror after breast cancer surgery (breast-conserving surgery or mastectomy) should, therefore, be prepared well and happen in a setting of privacy. Support for women who are particularly concerned about their altered appearance should be an integrative aspect of care [22].

A positive finding is that psychological functioning seems to improve within the first year postoperatively regardless of the type of surgical procedure [23,24]. The goal should be a patient-oriented approach that is oriented towards the needs of the woman and helps her to make the right decisions on the basis of comprehensive counseling.

\section{Conclusions for a Patient-Oriented Treatment Regimen}

The patient-doctor relationship plays a key role in a patient-oriented treatment. The surgeon ideally becomes a person of trust in a difficult life phase. Due to this trust, 
however, especially anxious or insecure patients tend to be influenced by their surgeon's preference for a surgical method.

The tight schedule of diagnosis, biopsy, and further treatments can be overwhelming and stop women from listening to their own needs, making it difficult to come to a decision they feel truly comfortable with. For this reason, it is important to support patients in finding the treatment that is ideal for their individual situation, which can range from mastectomy with immediate reconstruction to mastectomy without (or delayed) reconstruction.

We should keep in mind that breast reconstruction surgery will not solve major psychological problems, and the time needed for dealing with the psychosocial sequelae of the diagnosis and treatment cannot be shortened by any surgical procedure. Dissatisfaction with the decision or the result of the reconstruction might have its origin in unsolved psychosocial issues.

Enabling women to actively participate in the decision-making process is, therefore, a key step in the treatment $[25,26]$ to secure identification with the process of reconstruction and postoperative satisfaction. Extensive patient information ideally includes pictures and can help patients to come to a decision suitable for them.

The effects of the confrontation with human suffering on the surgeon should also be considered. Breast cancer surgeons can experience feelings of hopelessness, help- lessness, and fear - they too have daughters, wives, and mothers or are women themselves. Taking care of oneself and getting support when needed (intervision, supervision) can help dealing with these effects and also improve patient care.

A patient-oriented treatment regimen for breast cancer patients needs to look at the patient as a whole and her support system. Patients should be encouraged and supported in getting psychological support if needed. Many different methods and therapies have been established [27-29] to encourage breast cancer patients and their families. These therapies should be used if necessary.

More research in the field of psychosocial effects of breast cancer and needs of breast cancer patients will hopefully offer more insight into the situation of women with this diagnosis without letting us forget about the individual nature of each patient.

\section{Statement of Ethics}

The authors have no ethical conflicts to disclose.

\section{Disclosure Statement}

The authors have no conflicts of interest to declare.

\section{References}

1 Deutsche Krebsgesellschaft [Internet]. Basisinformation Krebs: Wie häufig ist Brustkrebs. Berlin [cited 2019 June 9]. Available from: https://www.krebsgesellschaft.de/ onko-internetportal/basis-informationenkrebs/krebsarten/brustkrebs-definition-undhaeufigkeit.html

2 Kardinal Schwarzenberg Klinikum [Internet]. Brustkrebs in Zahlen. Schwarzach im Pongau [cited 2019 June 9]. Available from: http://www.breastcare.at/brustkrebs/brustkrebs-in-zahlen

3 Robert Koch-Institut, Zentrum für Krebsregisterdaten [Internet]. Krebsarten: Brustkrebs. Berlin [cited 2019 June 9]. Available from: https://www.krebsdaten.de/Krebs/DE/Content/Krebsarten/Brustkrebs/brustkrebs_ node.html

4 Bertz J, Dahm S, Haberland J, Kraywinkel K, Kurtz BM, Wolf U. Verbreitung von Krebserkrankungen in Deutschland: Entwicklung der Prävalenzen zwischen 1990 und 2010. In: Robert Koch Institut [Internet]. [cited 2019 June 18]. Available from: https://edoc.rki.de/ handle/176904/3226

5 White CA. Body image dimensions and cancer: a heuristic cognitive behavioural model. Psychooncology. 2000 May-Jun;9(3):183-92.

6 Martino ML, Lemmo D, Gargiulo A, Barberio D, Abate V, Avino F, et al. Underfifty Women and Breast Cancer: Narrative Markers of
Meaning-Making in Traumatic Experience. Front Psychol. 2019 Mar;10:618.

7 Weis J. Die Psychoonkologie und ihre Bedeutung für die Krebsmedizin: Aktuelle Entwicklungstrends und zukünftige Forschungsaufgaben. Onkologie. 2001 Feb;24 Suppl 1:74-9.

8 Bergelt C, Schölermann C, Hahn I, Weis J, Koch U. Psychoonkologische Versorgung von Brustkrebspatientinnen im Krankenhaus und im ambulanten Sektor. Gesundheitswesen. 2010 Oct;72(10):700-6.

9 Catania AM, Sammut Scerri C, Catania GJ. Men's experience of their partners' breast cancer diagnosis, breast surgery and oncological treatment. J Clin Nurs. 2019 May;28(910):1899-910.

10 Jabłoński MJ, Streb J, Mirucka B, Słowik AJ, Jach R. The relationship between surgical treatment (mastectomy vs. breast conserving treatment) and body acceptance, manifesting femininity and experiencing an intimate relation with a partner in breast cancer patients. Psychiatr Pol. 2018 Oct;52(5):859-72.

11 Streb J, Jabłoński MJ, Słowik A, Babczyk D, Jach R. Indications for sexology consultation in women after surgical treatment due to breast cancer. Ann Agric Environ Med. 2019 Jun;26(2):379-84

12 Inhestern L, Bergelt C. When a mother has cancer: strains and resources of affected families from the mother's and father's perspective
- a qualitative study. BMC Womens Health. 2018 May; 18(1):72.

13 Drageset S, Lindstrøm TC, Ellingsen S. "I have both lost and gained." Norwegian survivors' experiences of coping 9 years after primary breast cancer surgery. Cancer Nurs. 2018 Oct; 1.

14 Denford S, Harcourt D, Rubin L, Pusic A. Understanding normality: a qualitative analysis of breast cancer patients concepts of normality after mastectomy and reconstructive surgery. Psychooncology. 2011 May;20(5):553-8.

15 Pikler V, Winterowd C. Racial and body image differences in coping for women diagnosed with breast cancer. Health Psychol. 2003 Nov;22(6):632-7.

16 Ananian P, Houvenaeghel G, Protière C, Rouanet P, Arnaud S, Moatti JP, et al. Determinants of patients' choice of reconstruction with mastectomy for primary breast cancer. Ann Surg Oncol. 2004 Aug;11(8):762-71.

17 Boman LE, Sandelin K, Wengström Y, Silén C. Patients' participation during treatment and care of breast cancer - a possibility and an imperative. Eur J Oncol Nurs. 2018 Dec;37: 35-42.

18 Abu-Nab Z, Grunfeld EA. Satisfaction with outcome and attitudes towards scarring among women undergoing breast reconstructive surgery. Patient Educ Couns. 2007 May;66(2):243-9. 
19 Pusic AL, Matros E, Fine N, Buchel E, Gordillo GM, Hamill JB, et al. Patient-Reported Outcomes 1 Year After Immediate Breast Reconstruction: Results of the Mastectomy Reconstruction Outcomes Consortium Study. J Clin Oncol. 2017 Aug;35(22):2499-506.

20 Harcourt D, Rumsey N. Mastectomy patients' decision-making for or against immediate breast reconstruction. Psychooncology. 2004 Feb;13(2):106-15.

21 Heimes AS, Stewen K, Hasenburg A. Psychosocial Aspects of Immediate versus Delayed Breast Reconstruction. Breast Care (Basel). 2017 Dec;12(6):374-7.

22 Paraskeva N, Herring B, Tollow P, Harcourt D. First look: A mixed-methods study exploring women's initial experiences of their appearance after mastectomy and/or breast reconstruction. J Plast Reconstr Aesthet Surg. 2019 Apr;72(4):539-47.
23 Harcourt DM, Rumsey NJ, Ambler NR, Cawthorn SJ, Reid CD, Maddox PR, et al. The psychological effect of mastectomy with or without breast reconstruction: a prospective, multicenter study. Plast Reconstr Surg. 2003 Mar; 111(3):1060-8.

24 Lardi AM, Myrick ME, Haug M, Schaefer DJ, Bitzer J, Simmen U, et al. The option of delayed reconstructive surgery following mastectomy for invasive breast cancer: why do so few patients embrace this offer? Eur J Surg Oncol. 2013 Jan;39(1):36-43.

25 Soon PS, Ruban S, Mo HT, Lee R, Saliba L, Shah A, et al. Understanding patient choices regarding breast reconstruction after mastectomy for breast cancer. Support Care Cancer. 2019 Jun;27(6):2135-42.
26 Kuo NT, Kuo YL, Lai HW, Ko NY, Fang SY. The influence of partner involvement in the decision-making process on body image and decision regret among women receiving breast reconstruction. Support Care Cancer. 2019 May;27(5):1721-8.

27 Modica C, Hoenig K. Mindfulness in FollowUp Care After Breast Cancer: Can It Prevent Recurrence? Breast Care (Basel). 2018 Apr; 13(2):102-8.

28 Lewis-Smith H, Diedrichs PC, Harcourt D. A pilot study of a body image intervention for breast cancer survivors. Body Image. 2018 Dec;27:21-31.

29 Lewis-Smith H, Diedrichs PC, Rumsey N, Harcourt D. Efficacy of psychosocial and physical activity-based interventions to improve body image among women treated for breast cancer: A systematic review. Psychooncology. 2018 Dec;27(12):2687-99. 